You might find this additional information useful...

This article cites 49 articles, 24 of which you can access free at:

http://jn.physiology.org/cgi/content/full/86/1/492\#BIBL

This article has been cited by 15 other HighWire hosted articles, the first 5 are:

The Transporters GlyT2 and VIAAT Cooperate to Determine the Vesicular Glycinergic Phenotype

K. R. Aubrey, F. M. Rossi, R. Ruivo, S. Alboni, G. C. Bellenchi, A. Le Goff, B. Gasnier and S. Supplisson

J. Neurosci., June 6, 2007; 27 (23): 6273-6281.

[Abstract] [Full Text] [PDF]

ERG Conductance Expression Modulates the Excitability of Ventral Horn GABAergic Interneurons That Control Rhythmic Oscillations in the Developing Mouse Spinal Cord F. Furlan, G. Taccola, M. Grandolfo, L. Guasti, A. Arcangeli, A. Nistri and L. Ballerini

J. Neurosci., January 24, 2007; 27 (4): 919-928.

[Abstract] [Full Text] [PDF]

Electrical Coupling between Locomotor-Related Excitatory Interneurons in the Mammalian Spinal Cord.

C. A. Hinckley and L. Ziskind-Conhaim

J. Neurosci., August 15, 2006; 26 (33): 8477-8483.

[Abstract] [Full Text] [PDF]

Ontogenic Changes of the Spinal GABAergic Cell Population Are Controlled by the Serotonin (5-HT) System: Implication of 5-HT1 Receptor Family

A.-E. Allain, P. Meyrand and P. Branchereau

J. Neurosci., September 21, 2005; 25 (38): 8714-8724.

[Abstract] [Full Text] [PDF]

Spatiotemporal Patterns of Dorsal Root-Evoked Network Activity in the Neonatal Rat Spinal Cord: Optical and Intracellular Recordings

L. Ziskind-Conhaim and S. Redman

J Neurophysiol, September 1, 2005; 94 (3): 1952-1961.

[Abstract] [Full Text] [PDF]

Medline items on this article's topics can be found at http://highwire.stanford.edu/lists/artbytopic.dtl on the following topics:

Physiology .. Synaptic Transmission

Neuroscience .. Glycine

Physiology .. Motor Neurons

Veterinary Science .. Spinal Cord

Neuroscience .. Gaba

Physiology .. Rats

Updated information and services including high-resolution figures, can be found at:

http://jn.physiology.org/cgi/content/full/86/1/492

Additional material and information about Journal of Neurophysiology can be found at: http://www.the-aps.org/publications/jn

This information is current as of June 17, 2007 . 


\title{
Transition From GABAergic to Glycinergic Synaptic Transmission in Newly Formed Spinal Networks
}

\author{
BAO-XI GAO, ${ }^{1}$ CHRISTIAN STRICKER, ${ }^{2}$ AND LEA ZISKIND-CONHAIM ${ }^{1}$ \\ ${ }^{1}$ Department of Physiology and Center for Neuroscience, University of Wisconsin Medical School, Madison, \\ Wisconsin 53706; and ${ }^{2}$ Institute of Neuroinformatics, University of Zürich and Federal Institute of Technology, \\ CH-8057 Zurich, Switzerland
}

Received 9 May 2000; accepted in final form 13 March 2001

Gao, Bao-Xi, Christian Stricker, and Lea Ziskind-Conhaim. Transition from GABAergic to glycinergic synaptic transmission in newly formed spinal networks. J Neurophysiol 86: 492-502, 2001. The role of glycinergic and GABAergic systems in mediating spontaneous synaptic transmission in newly formed neural networks was examined in motoneurons in the developing rat spinal cord. Properties of action potentialindependent miniature inhibitory postsynaptic currents (mIPSCs) mediated by glycine and $\mathrm{GABA}_{\mathrm{A}}$ receptors $\left(\mathrm{GlyR}\right.$ and $\left.\mathrm{GABA}_{\mathrm{A}} \mathrm{R}\right)$ were studied in spinal cord slices of 17- to 18-day-old embryos (E17-18) and 1- to 3-day-old postnatal rats (P1-3). mIPSC frequency and amplitude significantly increased after birth, while their decay time decreased. To determine the contribution of glycinergic and GABAergic synapses to those changes, GlyR- and $\mathrm{GABA}_{\mathrm{A}} \mathrm{R}$-mediated mIPSCs were isolated based on their pharmacological properties. Two populations of pharmacologically distinct mIPSCs were recorded in the presence of glycine or $\mathrm{GABA}_{\mathrm{A}}$ receptors antagonists: bicuculline-resistant, fast-decaying GlyRmediated mIPSCs, and strychnine-resistant, slow-decaying $\mathrm{GABA}_{\mathrm{A}} \mathrm{R}$ mediated mIPSCs. The frequency of $\mathrm{GABA}_{\mathrm{A}} \mathrm{R}$-mediated mIPSCs was fourfold higher than that of GlyR-mediated mIPSCs at E17-18, indicating that GABAergic synaptic sites were functionally dominant at early stages of neural network formation. Properties of $\mathrm{GABA}_{\mathrm{A}} \mathrm{R}$-mediated mIPSC amplitude fluctuations changed from primarily unimodal skewed distribution at E17-18 to Gaussian mixtures with two to three discrete components at $P 1-3$. A developmental shift from primarily long-duration GABAergic mIPSCs to short-duration glycinergic mIPSCs was evident after birth, when the frequency of GlyR-mediated mIPSCs increased 10-fold. This finding suggested that either the number of glycinergic synapses or the probability of vesicular glycine release increased during the period studied. The increased frequency of GlyR-mediated mIPSCs was associated with more than a twofold increase in their mean amplitude, and in the number of motoneurons in which mIPSC amplitude fluctuations were best fitted by multi-component Gaussian curves. A third subpopulation of mIPSCs was apparent in the absence of glycine and $\mathrm{GABA}_{\mathrm{A}}$ receptor antagonists: mIPSCs with both fast and slow decaying components. Based on their dual-component decay time and their suppression by either strychnine or bicuculline, we assumed that these were generated by the activation of co-localized postsynaptic glycine and $\mathrm{GABA}_{\mathrm{A}}$ receptors. The contribution of mixed glycine-GABA synaptic sites to the generation of mIPSCs did not change after birth. The developmental switch from predominantly long-duration GABAergic inhibitory synaptic currents to short-duration glycinergic currents might serve as a mechanism regulating neuronal excitation in the developing spinal networks.

Address for reprint requests: L. Ziskind-Conhaim, Dept. of Physiology, 129 SMI, 1300 University Ave., University of Wisconsin Medical School, Madison, WI 53706 (E-mail: lconhaim@physiology.wisc.edu).

\section{N T R O D U C T I O N}

Glycine and $\gamma$-aminobutyric acid (GABA) are the primary inhibitory neurotransmitters in mammalian spinal cord and brain stem (Curtis et al. 1968; Krnjevic et al. 1977; Schneider and Fyffe 1992; Werman et al. 1968; Yoshimura and Nishi 1995; reviewed by Davidoff and Hackman 1983; Young and Macdonald 1983). The two neurotransmitters activate pharmacologically distinct ionotropic receptors that are permeable to chloride ions. Immunohistochemical studies have shown that glycine- and GABA-like immunoreactivity are coexpressed in spinal neurons, and that the extent of their coexistence in nerve terminals depends on the laminae (reviewed by Todd and Spike 1993). Furthermore, glycine and GABA receptors are co-localized at postsynaptic sites in various layers of the spinal cord (Bohlhalter et al. 1994; Örnung et al. 1994; Todd and Sullivan 1990; Todd et al. 1996), indicating a possible synergism in the function of the two amino acids in spinal neurons. Support for mixed glycine-GABA synaptic sites with synergistic action was demonstrated in recent electrophysiological and morphological findings proposing that glycine and GABA are not only coexpressed in the same nerve terminals, but are also co-stored in synaptic vesicles in presynaptic terminals making synaptic contacts on sensory and motoneurons (Chaudhry et al. 1998; Chéry and Koninck 1999; Jonas et al. 1998). It has been hypothesized that simultaneous activation of glycine and $\mathrm{GABA}_{\mathrm{A}}$ receptors that produces dual-component, fast- and slow-decaying synaptic currents might play a role in the finetuning of synaptic integration in the spinal cord.

The roles of glycine and GABA in mediating inhibitory synaptic transmission have been studied extensively in the rodent spinal cord, but little is known about their relative contribution to synaptic transmission during the period of neural network formation. In a previous study we have suggested that the density of $\mathrm{GABA}_{\mathrm{A}}$ receptors expressed in embryonic motoneurons is higher than that of glycine receptors, as evident by the threefold larger GABA- than glycineinduced somatic currents generated by exogenous applications of the neurotransmitters (Gao and Ziskind-Conhaim 1995). A large increase in glycine currents is apparent after birth, when the two agonists produce somatic currents with similar amplitudes. The high density of GABA-gated currents is temporally

The costs of publication of this article were defrayed in part by the payment of page charges. The article must therefore be hereby marked "advertisement" in accordance with 18 U.S.C. Section 1734 solely to indicate this fact. 
correlated with the transient appearance of GABA immunoreactivity in most developing spinal neurons (Ma et al. 1992; Walton et al. 1993). The functional importance of the abundant expression of GABA in embryonic spinal cord is unknown, but it has been hypothesized that in addition to its role as neurotransmitter, GABA is a neurotrophic substance that modulates neuronal development and synaptogenesis (reviewed by Lauder 1993; Meier et al. 1991; Ziskind-Conhaim 1998). GABA and glycine depolarize neurons in the developing rodent spinal cord (Gao and Ziskind-Conhaim 1995; Takahashi 1984; Wu et al. 1992), resulting in the activation of voltagedependent $\mathrm{Ca}^{2+}$ channels and transient elevation of cytoplasmic $\mathrm{Ca}^{2+}$ (Reichling et al. 1994; Ziskind-Conhaim 1998). It is likely that the relatively long-duration GABAergic currents (Chéry and Koninck 1999; Yoshimura and Nishi 1995) are more effective than the glycinergic currents in triggering transient increase in intracellular $\mathrm{Ca}^{2+}$. The increased cytoplasmic $\mathrm{Ca}^{2+}$ might initiate cellular mechanisms underlying neuronal development and neural network formation (Fields and Nelson 1993; Gosh et al. 1993; Kocsis et al. 1993; Spitzer 1994).

The primary objective of our study was to determine the relative contribution of pure and mixed glycine and GABA synaptic sites to spontaneous inhibitory transmission during the period of extensive synaptogenesis in the mammalian spinal cord. Experiments were designed to determine whether developmental changes in synaptic transmission are associated with changes in presynaptic transmitter release and/or in properties of postsynaptic receptors/channels of the two neurotransmitters systems.

Preliminary data from this study have been presented in an abstract form (Gao and Ziskind-Conhaim 1999).

\section{METHODS}

\section{Spinal cord preparation}

Lumbar spinal cords were isolated from Sprague-Dawley rat embryos at 17-18 days of gestation (E17-18, birth is at E21-22), and from 1- to 3-day-old postnatal rats $(P 1-3)$. The procedure for spinal cord dissection was similar to that described previously (Gao et al. 1998). A pregnant rat was lightly anesthetized with ether, decapitated, and embryos were removed into cold dissection solution and decapitated. Postnatal rats were anesthetized by hypothermia. The lumbar region of the spinal cord was removed after ventral laminectomy and placed in oxygenated cold dissection solution. The dissection solution contained (in mM) $140 \mathrm{NaCl}, 5 \mathrm{KCl}, 4 \mathrm{CaCl}_{2}, 1.1 \mathrm{MgCl}_{2}, 4.2 \mathrm{HEPES}$, and 11 glucose ( $\mathrm{pH} 7.2-7.4)$. The isolated spinal cord was embedded in agar (2\% in extracellular solution). Transverse slices, $350 \mu \mathrm{m}$ thick, were cut using a Vibratome (Technical Products International). Prior to whole cell recordings, slices were incubated in extracellular solution at room temperature for $1 \mathrm{~h}$. The extracellular solution contained (in $\mathrm{mM}$ ) $113 \mathrm{NaCl}, 3 \mathrm{KCl}, 2 \mathrm{CaCl}_{2}, 1 \mathrm{MgCl}_{2}, 25 \mathrm{NaHCO}_{3}, 1$ $\mathrm{NaH}_{2} \mathrm{PO}_{4}$, and 11 glucose. The solution was equilibrated with $95 \%$ $\mathrm{O}_{2}-5 \% \mathrm{CO}_{2}\left(\mathrm{pH} 7.2\right.$ at $\left.20-22^{\circ} \mathrm{C}\right)$.

\section{Whole cell recording}

Slices were transferred into a recording chamber, which was mounted on the stage of an upright microscope and were superfused with aerated extracellular solution at room temperature. Whole cell patch-clamp recordings were carried out in visually identified large neurons in the medial and lateral ventral horn using infrared differential interference contrast (DIC) optics (Gao et al. 1998; MacVicar 1984). These neurons were assumed to be motoneurons. Patch elec- trodes were pulled to tip resistances of 3-5 M $\Omega$ using a multi-stage puller (Sutter Instruments). Electrodes were filled with solution composed of (in mM) $149 \mathrm{CsCl}, 10 \mathrm{HEPES}, 0.2$ EGTA, $1 \mathrm{Mg}$-ATP, and 0.1 GTP. The solution was adjusted to $\mathrm{pH} 7.2$ using $\mathrm{CsOH}$, and the osmolarity was $290 \mathrm{mOsm}$. Recordings were carried out at room temperature $\left(20-22^{\circ} \mathrm{C}\right)$. After the formation of a giga-ohm seal and membrane rupture to obtain whole cell recording, the cell capacitance and series resistance were electronically compensated. Typically, the series resistance was two- to threefold higher than the pipette resistance and was compensated by $>60 \%$. Recordings were carried out only in neurons in which depolarizing test pulses produced fast voltage-dependent inward $\mathrm{Na}^{+}$current.

To record action potential-independent miniature inhibitory postsynaptic currents (mIPSCs), TTX $(1 \mu \mathrm{M})$ was added to the extracellular solution to block voltage-gated $\mathrm{Na}^{+}$current. In the presence of TTX, mIPSC frequency was approximately $0.1 \mathrm{~Hz}$ at $E 17-18$ and $0.3 \mathrm{~Hz}$ at $P 1-3$ (Gao et al. 1998).

To acquire a large sample of mIPSCs for statistical analysis, experiments were performed in high extracellular $\mathrm{K}^{+}(18 \mathrm{mM})$. High- $\mathrm{K}^{+}$-induced increase in mIPSC frequency does not result in a significant number of summating miniature currents (Gao et al. 1998). Recordings were carried out at a holding potential (HP) of $-60 \mathrm{mV}$. With $\mathrm{Cl}^{-}$equilibrium potential close to $0 \mathrm{mV}$, mIPSCs appeared as inward currents. To increase the kinetic differences between glycine and GABA mIPSCs, the experiments discussed in this manuscript were carried out in the presence of flunitrazepam (Flu, $2 \mu \mathrm{M}$ ), a benzodiazepine that selectively slows the decay of $\mathrm{GABA}_{\mathrm{A}} \mathrm{R}$-mediated mIPSCs (Mellor et al. 1997). Glutamate-mediated excitatory postsynaptic currents (EPSCs) were blocked by D-2-amino-5-phosphonovaleric acid (D-APV, $20 \mu \mathrm{M}$ ), a $N$-methylD-aspartate (NMDA) receptor antagonist, and 6-cyano-7-nitroquinoxaline-2,3-dione (CNQX, 5-10 $\mu \mathrm{M}$ ), a non-NMDA receptor antagonist. Synaptic currents were recorded using either Axopatch-1D or Axopatch 200A amplifiers (Axon Instruments). Currents were filtered at $1 \mathrm{kHz}$, digitized at $5 \mathrm{kHz}$, and stored on optical disk for later analysis. Continuous recordings were carried out for $10 \mathrm{~min}$ or until $>150 \mathrm{mIPSCs}$ were recorded at E17-18, and $>250$ events were recorded at $P 1-3$.

\section{Data analysis}

The threshold for detection of mIPSC was set at $2 \mathrm{pA}$ above the background noise. mIPSCs and events in the baseline noise were detected and measured using Mini Analysis software (Synaptosoft). Kinetic analysis was performed on averaged mIPSCs, which were obtained by lining up the rising phase of single mIPSCs. In most motoneurons, more than 100 events were averaged. Kinetic analysis included the following: peak amplitude, rise time from 10 to $90 \%$ peak amplitude, and decay time constant (decay $\tau$ ). In most mIPSCs, the time course of decay was best fitted with the sum of two exponentials, and amplitude-weighted decay $\tau \mathrm{s}$ were calculated by summing the two time constants, weighted by their fractional contribution to the amplitude. Data are presented as means \pm SE. Student's $t$-test was used to determine the statistical significance $(P<0.05)$.

\section{Statistical analysis of amplitude distributions}

Probability density functions (PDFs) were generated by convolving each mIPSC population with a normal distribution (Stricker et al. 1994) having a mean of zero and a standard deviation of the baseline noise. This standard deviation of the convolving normal distribution was chosen to account for the unimodality and the skewness of the distributions. Large amplitude mIPSCs that formed the tail of amplitude histograms (outliers) were removed to minimize the bias of the estimates. Amplitude histograms were plotted based on a binwidth of 2 pA.

The optimal parameters of each mode were determined using the 
E17

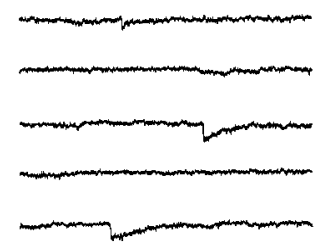

P2

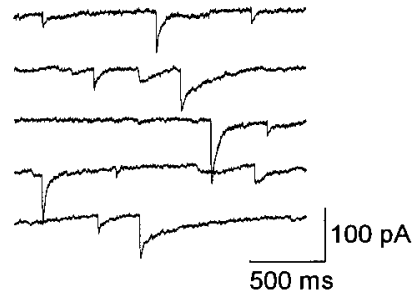

FIG. 1. Traces of continuously recorded miniature inhibitory postsynaptic currents (mIPSCs) in embryonic day 17 (E17) and postntatal day 2 (P2) motoneurons. mIPSC frequency was lower at $E 17(0.3 \mathrm{~Hz})$ than at $P 2(1.1 \mathrm{~Hz})$. Larger amplitude and shorter duration mIPSCs were more evident at $P 2$ than at E17. Recordings shown in this and all other figures were performed in the presence of D-2-amino-5-phosphonovaleric acid (D-APV; $20 \mu \mathrm{M}$ ) and 6-cyano-7-nitroquinoxaline-2,3-dione (CNQX; $10 \mu \mathrm{M})$, and at a holding potential (HP) of $-60 \mathrm{mV}$. Under our experimental conditions, $E_{\mathrm{Cl}}$ was close to $0 \mathrm{mV}$, and mIPSCs were recorded as inward currents.

Expectation-Maximization algorithm. The formulas required were those derived by Stricker and Redman (1994). The algorithm corresponded to that for optimal fitting of the noise. The Gaussians in the mixture were constrained to be equal or larger than the noise variance.

Statistical procedures were designed to allow a systematic evaluation of possible models of synaptic transmission that might have generated the amplitude distribution of mIPSCs, using a null hypothesis for rejection in each case. The null hypothesis test was based on the ability of each model to fit the measured PDF. When the null hypothesis could not be rejected, the model with the smaller number of components was accepted (principle of parsimony). In the first step of the statistical analysis, the minimum number of Gaussian distributions required to fit the PDF was determined. This was achieved when the addition of a further Gaussian distribution did not result in a significantly better fit. In the second step, a single skewed PDF was fitted to mIPSC amplitude distribution. Three skewed PDFs were tested: the gamma, weibull, and cubic transform of a random Gaussian variable. In this test, the skewed PDF became the null hypothesis, while the optimal mixture of Gaussians became the alternative hypothesis. To determine the quality of each model to describe the PDF, the two models were compared using the Wilks statistic as described by Stricker et al. (1994). If all three null hypotheses could be rejected, balanced bootstrap samples were generated to estimate the errors of the parameters describing the PDFs.

\section{RES ULTS}

\section{Developmental changes in MIPSC properties}

mIPSC properties were examined at E17-18, when excitatory monosynaptic connections are first formed on motoneurons (Kudo and Yamada 1987; Ziskind-Conhaim 1990), and after birth $(P 1-3)$, when the frequency of spontaneous synaptic events significantly increases (Gao et al. 1998; Xie and Ziskind-Conhaim 1995; Ziskind-Conhaim 1988). Examples of

high- $\mathrm{K}^{+}$-induced mIPSCs recorded in E17 and P2 motoneurons are shown in Fig. 1. In those neurons, mIPSC frequencies were 0.3 and $1.1 \mathrm{~Hz}$ at $E 17$ and $P 2$, respectively. Characteristically, primarily long-duration mIPSCs were recorded in embryonic motoneurons, while shorter duration mIPSCs were evident after birth.

During the 8-day period studied, mIPSC frequency increased threefold: from $0.34 \pm 0.07$ (SE) $\mathrm{Hz}$ at E17-18 to $0.90 \pm 0.11 \mathrm{~Hz}$ at $P 1-3$ (Table 1). The higher frequency might be attributed to the formation of new inhibitory synaptic sites or an increased probability of transmitter release. It is unlikely that the postnatal increase in mIPSC frequency resulted from developmental changes in the effect of high extracellular $\mathrm{K}^{+}$ on synaptic transmission. High- $\mathrm{K}^{+}$solution produced a similar three- to fourfold increase in mEPSC and mIPSC frequencies in motoneurons of both embryonic $(n=3)$ and postnatal $(n=$ 3) rats (unpublished observations).

The developmental increase in mIPSC frequency was associated with an increase in the mean amplitude, changing from $40.4 \pm 7.2 \mathrm{pA}$ at $E 17-18(n=7)$ to $64.9 \pm 9.2 \mathrm{pA}$ at $P 1-3$ ( $n=7$, Table 1$)$. To determine whether the characteristics of mIPSC amplitude distribution changed during this period, analyses of PDFs were performed in seven motoneurons in each age group. Based on the quantal theory of transmitter release, miniature currents are generated by the release of single vesicles (del Castillo and Katz 1954; Isaacson and Walmsley 1995; Redman 1990). Therefore the first component in multiple-component Gaussian curves (e.g., Fig. 3D) represents the unitary current generated by the release of a single vesicle, and the additional components might be attributed to multi-vesicular release. Our findings showed that in $71 \%(n=$ $5 / 7$ ) of embryonic motoneurons, mIPSC amplitude fluctuations were best fitted by Gaussian mixtures with two to three discrete components. After birth, $86 \%(n=6 / 7)$ of motoneurons exhibited mIPSC amplitude fluctuations that were best fitted with multiple Gaussian curves with two to six distinct peaks. The estimated size of the first component was $19.4 \pm 3.4 \mathrm{pA}(n=$ 5) at E17-18, not significantly smaller than the $33.9 \pm 8.2 \mathrm{pA}$ $(n=6)$ recorded after birth (Table 1$)$.

To determine whether the basic kinetic properties of mIPSCs changed after birth, rise time and decay $\tau$ s of averaged mIPSCs were analyzed. Our findings showed that, while there was no change in mIPSC rise time, significantly shorter mIPSC decay $\tau \mathrm{s}$ were apparent after birth. Decay $\tau 1$ decreased from $84.4 \pm$ $8.1 \mathrm{~ms}$ at $E 17-18$ to $25.8 \pm 3.3 \mathrm{~ms}$ at $P 1-3$, and a similar threefold decrease was estimated for decay $\tau 2$, which was reduced from $441.0 \pm 47.4 \mathrm{~ms}$ at $E 17-18$ to $139.8 \pm 9.1 \mathrm{~ms}$ at P1-3 (Table 1). At both ages, $\tau 1$ contributed approximately $65 \%$ to the peak amplitude, and amplitude-weighted mean

TABLE 1. Developmental changes in MIPSC properties recorded in spinal motoneurons of E17-18 and P1-3 rats

\begin{tabular}{lrcccccc}
\hline \hline & $n$ & Frequency, Hz & Mean Amplitude, pA & Unitary Current, pA & Rise Time, ms & Decay $\tau 1, \mathrm{~ms}$ & Decay $\tau 2, \mathrm{~ms}$ \\
\hline E17-18 & 7 & $0.34 \pm 0.07$ & $40.4 \pm 7.2(7)$ & $19.4 \pm 3.4(5)$ & $2.8 \pm 0.4$ & $84.4 \pm 8.1$ & $441.0 \pm 47.4$ \\
$P 1-3$ & 11 & $0.90 \pm 0.11^{*}$ & $64.9 \pm 9.2(7)$ & $33.9 \pm 8.2(6)$ & $2.3 \pm 0.3$ & $25.8 \pm 3.3 *$ & $139.8 \pm 9.1 *$ \\
\hline
\end{tabular}

Values are means $\pm \mathrm{SE} ; n$ is number of motoneurons; number of motoneurons is in parentheses. Miniature inhibitory postsynaptic current (mIPSC) frequency

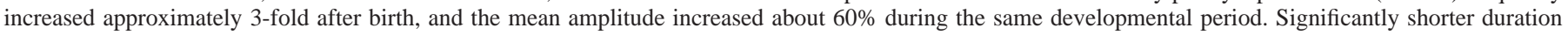

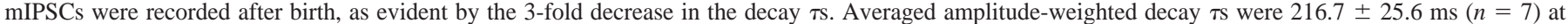

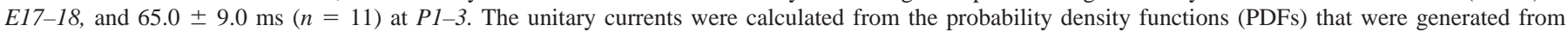
mIPSCs recorded in 7 motoneurons in each age group. * Significantly different than at E17-18, $P<0.05$. 
decay $\tau$ s were $216.7 \pm 25.6(n=7)$ and $65.0 \pm 9.0(n=11)$ before and after birth, respectively.

To rule out the possibility that the decrease in decay $\tau \mathrm{s}$ resulted from a developmental decrease in membrane resistance (e.g., Xie and Ziskind-Conhaim 1995; Ziskind-Conhaim 1988 ), decay $\tau \mathrm{s}$ of $10 \%$ of mIPSCs with the fastest rise time were analyzed. It was assumed that the fastest rising mIPSCs were generated near the soma and therefore were adequately voltage clamped and not influenced by changes in membrane resistance. Decay $\tau \mathrm{s}$ could not be used as a criterion for the isolation of fast mIPSCs that were generated close to the soma, because glycinergic and GABAergic mIPSCs had different decay $\tau$ s (see Table 2). The averaged rise time of the fastest mIPSCs was twofold faster than that estimated for the entire mIPSC population: $1.01 \pm 0.13 \mathrm{~ms}$ at E17-18 and $1.36 \pm 0.15$ $\mathrm{ms}$ at $P 1-3$ (Fig. 2). Similar to the developmental decrease in decay $\tau \mathrm{s}$ of the entire population of mIPSCs, the decay $\tau \mathrm{s}$ of the fastest mIPSCs decreased two- to threefold after birth. Decay $\tau 1$ decreased from $57.6 \pm 6.6 \mathrm{~ms}$ at $E 17-18$ to $22.2 \pm$ $3.3 \mathrm{~ms}$ at $P 1-3$, and shorter $\tau 2$ was also apparent during the same period: changing from $323.2 \pm 55.5 \mathrm{~ms}$ to $107.3 \pm 14.7$. This finding supported our hypothesis that the developmental decrease in decay $\tau \mathrm{s}$ was not related to the age-dependent decrease in membrane resistance.

\section{Frequency and amplitude of GlyR-mediated mIPSCs increased after birth}

To determine the contribution of glycinergic and GABAergic synaptic transmission to the developmental changes in mIPSC properties, GlyR- and $\mathrm{GABA}_{\mathrm{A}} \mathrm{R}$-mediated mIPSCs were isolated pharmacologically using specific glycine and $\mathrm{GABA}_{\mathrm{A}}$ receptors antagonists. GlyR-mediated mIPSCs were recorded in the presence of bicuculline methiodide $(5-10 \mu \mathrm{M})$, a GABA ${ }_{A}$ R antagonist (Figs. $3 A$ and $4 A$ ). Bicuculline-resistant mIPSCs were blocked by strychnine $(0.4-0.5 \mu \mathrm{M})$, a GlyR antagonist (not shown), indicating that those were GlyR-mediated mIPSCs. Examples of traces representing averaged GlyR-mediated mIPSCs at $E 18$ and $P 2$ are shown in Figs. $3 B$ and $4 B$.

The frequency of GlyR-mediated mIPSCs increased 10-fold between E17-18 and P1-3 (Table 2), suggesting a substantial increase in either the number of functional glycinergic synapses and/or in the probability of high- $\mathrm{K}^{+}$-induced spontaneous presynaptic release of glycine during the period studied.

The mean amplitude of GlyR-mediated mIPSCs increased twofold after birth, changing from $20.1 \pm 4.4 \mathrm{pA}(n=5)$ at
E17

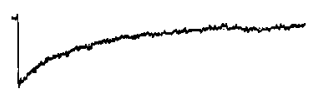

\section{P3}

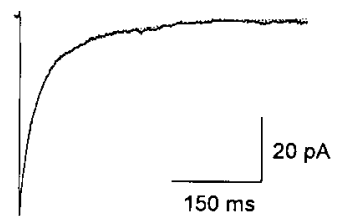

FIG. 2. Averages of $10 \%$ of mIPSCs with the fastest rise times in $E 17$ and $P 3$ motoneurons. At $E 17$, averaged mIPSC rise time was $1.5 \mathrm{~ms}$, and $\tau 1$ and $\tau 2$ were 71.6 and $358.2 \mathrm{~ms}$, respectively ( $n=32$ events). At $P 3$, the rise time was $1.0 \mathrm{~ms}$, and $\tau 1$ and $\tau 2$ were 22.1 and $118.3 \mathrm{~ms}$, respectively $(n=71$ events).
A

bicuculline
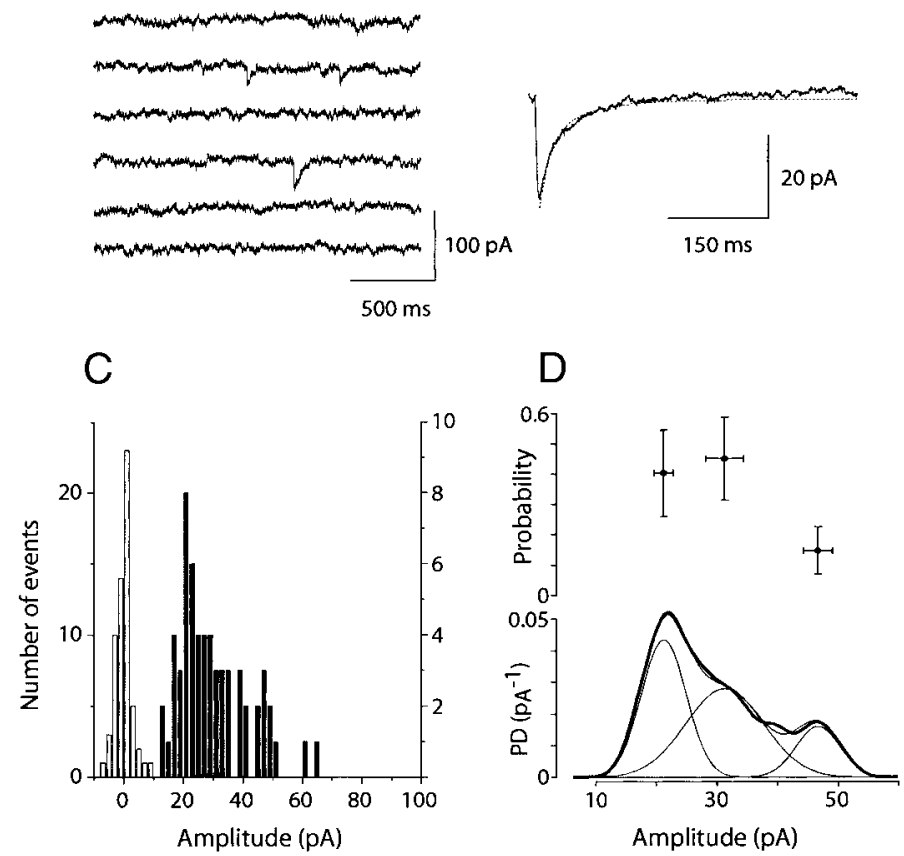

FIG. 3. Properties of GlyR-mediated mIPSCs recorded in an E18 motoneuron. The frequency of fast-decaying, bicuculline-resistant inward currents was $0.13 \mathrm{~Hz}(A)$. Those mIPSCs were blocked by $0.4 \mu \mathrm{M}$ strychnine (not shown). The rise time of the averaged GlyR-mediated mIPSC ( $n=50$ events) was 3.0 $\mathrm{ms}(B)$. In this, and all other figures, the time course of decay was best fit with 2 exponentials $(\cdots)$. Decay $\tau 1$ and $\tau 2$ were 15.8 and $78.8 \mathrm{~ms}$, respectively. Amplitude histograms of mIPSCs and noise fluctuations ( $\square$ and $\square$, respectively) are shown in $C$. In this and all other figures, the numbers of noise events are marked along the left vertical axis, and the numbers of mIPSCs are marked along the right vertical axis. Probability density (PD) as a function of mIPSC amplitude was generated from a sample size of 56 observations and based on a noise standard deviation of $2.3 \mathrm{pA}(D)$. mIPSC amplitudes larger than $60 \mathrm{pA}$ (outliers) were removed to minimize the bias of the estimates. Three discrete components were identified at $21.2 \pm 1.6,31.3 \pm 3.1$, and $46.6 \pm 2.4 \mathrm{pA}(D$, bottom). The associated standard deviations were $3.7 \pm 0.6,6.4 \pm 1.3$, and $3.6 \pm 0.9 \mathrm{pA}$, respectively. The component probabilities were $0.40 \pm 0.14$, $0.45 \pm 0.14$, and $0.15 \pm 0.08(D$, top $)$.

E17-18 to $42.4 \pm 8.8 \mathrm{pA}(n=9)$ at $P 1-3$ (Table 2). Several factors might contribute to the increase in mIPSC amplitude including a developmental increase in quantal size, higher density of postsynaptic receptors, larger channel conductance, and increased probability of multiple vesicular releases. To determine whether the developmental increase in mean amplitude was associated with changes in the characteristics of mIPSC amplitude distribution, analyses of PDFs were performed in five embryonic and nine postnatal motoneurons. Our findings showed that in $60 \%(n=3 / 5)$ of E17-18 motoneurons, GlyR-mediated mIPSC amplitude fluctuations were best fitted by a Gaussian mixture with two to three discrete components, and the size of the first component was $17.6 \pm 2.1 \mathrm{pA}$. In contrast, in all P1-3 motoneurons $(n=9 / 9)$, mIPSC amplitude fluctuations were best fitted by Gaussian mixtures with two to four components, but the size of the first component, $22.6 \pm 3.5 \mathrm{pA}(n=9)$, was similar to that measured at E17-18 (Table 2).

The rise and decay times of GlyR-mediated mIPSCs did not change after birth. The rise time was $3.0 \pm 0.4 \mathrm{~ms}$ at E17-18 and $2.4 \pm 0.2 \mathrm{~ms}$ at $P 1-3$ (Table 2). Decay time constants 
A

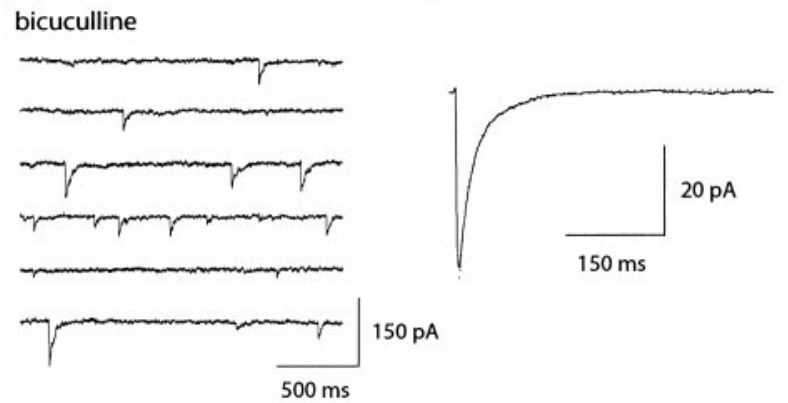

C

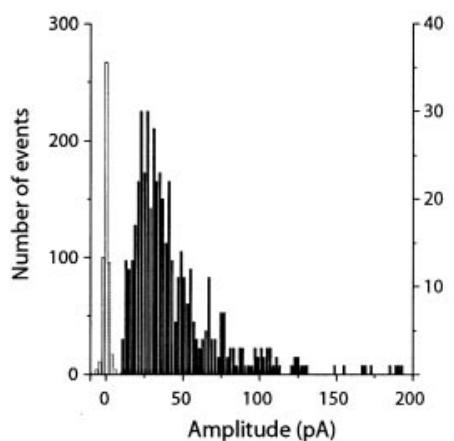

D

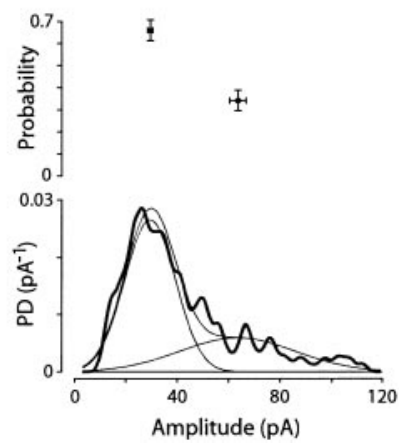

FIG. 4. Properties of GlyR-mediated mIPSCs recorded in a $P 2$ motoneuron. Higher frequency and larger amplitude mIPSCs were recorded at $P 2$ than at E17 (Fig. 1). mIPSC frequency was $1.0 \mathrm{~Hz}$ in the presence of bicuculline $(A)$. The rise time of the averaged mIPSC was $2.0 \mathrm{~ms}$, and decay $\tau 1$ and $\tau 2$ were 14.7 and $67.0 \mathrm{~ms}$, respectively $(n=371$ events; $B)$. Amplitude histograms of mIPSCs and noise fluctuations are shown in $C$. PD as a function of mIPSC amplitude was produced from a sample size of 502 observations and based on a noise standard deviation of $1.7 \mathrm{pA}(D)$. To minimize the bias of the estimates, mIPSC amplitudes larger than $120 \mathrm{pA}$ were not analyzed. Two distinct components were identified at $29.4 \pm 1.2$ and $63.4 \pm 3.2 \mathrm{pA}(D$, bottom $)$. The associated standard deviations were $9.9 \pm 0.7$ and $22.8 \pm 0.9 \mathrm{pA}$, respectively. The component probabilities were $0.66 \pm 0.05$ and $0.34 \pm 0.05(D$, top $)$.

ranged from 13.0 to $14.4 \mathrm{~ms}$ for $\tau 1$ and 64.8 to $70.0 \mathrm{~ms}$ for $\tau 2$ (Table 2). At both ages, $\tau 1$ contributed $67 \%$ to the peak amplitude, and amplitude-weighted mean decay $\tau$ s were $30.4 \pm 6.7 \mathrm{~ms}(n=$ $7)$ at $E 17-18$, and $33.6 \pm 3.1 \mathrm{~ms}(n=11)$ at $P 1-3$.

\section{Frequency and amplitude of $G A B A_{A} R$-mediated mIPSCs did not change after birth}

$\mathrm{GABA}_{\mathrm{A}} \mathrm{R}$-mediated mIPSCs were recorded in the presence of strychnine $(0.4-0.5 \mu \mathrm{M}$, Figs. $5 A$ and $6 A)$, a selective

A

strychnine

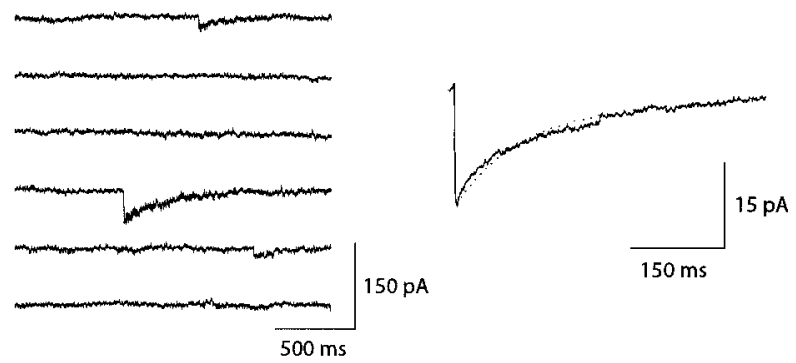

C
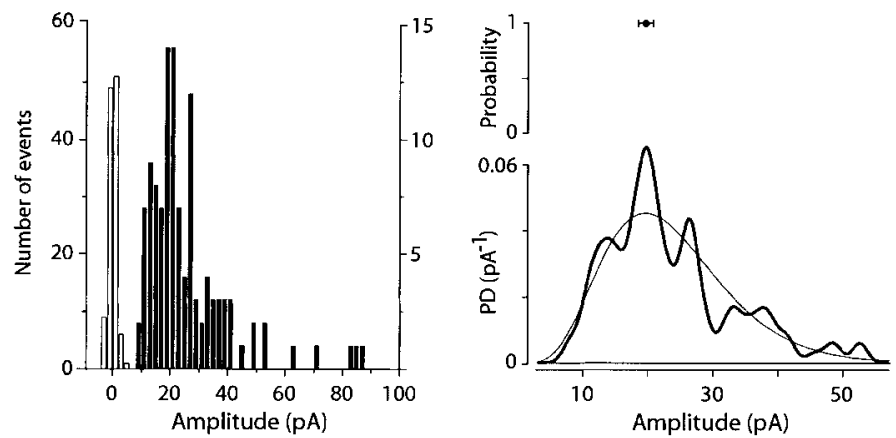

FIG. 5. Properties of GABA ${ }_{A}$ R-mediated mIPSCs recorded in an $E 17$ motoneuron. In the presence of strychnine, mIPSC frequency was $0.2 \mathrm{~Hz}(A)$. Those mIPSCs were blocked by bicuculline (not shown). Rise time of the averaged GABAergic mIPSC ( $n=116$ events) was $1.0 \mathrm{~ms}$, and decay $\tau 1$ and $\tau 2$ were 88.7 and $443.3 \mathrm{~ms}$, respectively $(B)$. Amplitude histograms of mIPSCs and noise fluctuations are shown in $C$. PD as a function of mIPSC amplitude was generated from a sample size of 110 observations and based on a noise standard deviation of $1.2 \mathrm{pA}(D)$. mIPSC amplitudes larger than $60 \mathrm{pA}$ were removed to minimize the bias of the estimates. The null hypothesis of a skewed amplitude distribution could not be rejected for this motoneuron. The peak of the gamma distribution was identified at $19.6 \pm 1.2 \mathrm{pA}(D)$.

glycine receptor antagonist at concentrations $<1 \mu \mathrm{M}$ (Jonas et al. 1998). Strychnine-resistant mIPSCs were blocked by bicuculline (not shown), confirming that these were $\mathrm{GABA}_{\mathrm{A}} \mathrm{R}$ mediated mIPSCs. The frequency of $\mathrm{GABA}_{\mathrm{A}} \mathrm{R}$-mediated mIPSCs was $0.26 \mathrm{~Hz}$ at E17-18, fourfold higher than the frequency of GlyR-mediated mIPSCs (Table 2). The frequency of GABAergic currents did not change after birth, suggesting that there was no increase in the number of GABAergic synaptic sites on motoneurons.

The mean amplitude of GABAergic mIPSCs was $23.4 \pm 3.3$

TABLE 2. Developmental changes in the properties of pharmacologically isolated glycinergic and GABAergic mIPSCs

\begin{tabular}{|c|c|c|c|c|c|}
\hline & E17-18 & $P 1-3$ & E17-18 & & $P 1-3$ \\
\hline Mean amplitude, pA & $20.1 \pm 4.4(5)$ & $42.4 \pm 8.8(9)$ & $23.4 \pm 3.3(5)$ & 22.7 & $\pm 2.5 \dagger(9)$ \\
\hline Unitary current, pA & $17.6 \pm 2.1(3)$ & $22.6 \pm 3.5(9)$ & $15.6 \pm 1.1 \neq(1)$ & 17.9 & $\pm 2.9(7)$ \\
\hline Rise time, $\mathrm{ms}$ & $3.0 \pm 0.4$ & $2.4 \pm 0.2$ & $2.7 \pm 0.4$ & 3.3 & $\pm 0.2 \dagger$ \\
\hline Decay $\tau 1, \mathrm{~ms}$ & $13.0 \pm 2.8$ & $14.4 \pm 1.4$ & $90.1 \pm 12.4 \dagger$ & 60.8 & $\pm 5.9^{*} \dagger$ \\
\hline
\end{tabular}

Values are means $\pm \mathrm{SE}$; number of motoneurons for E17-18 is 7 and for P1-3 is 11 . The frequency and mean amplitude of GlyR-mediated mIPSCs significantly increased postnatally, and the duration of GABA ${ }_{A} R$-mediated mIPSCs significantly decreased. PDFs were generated in 5 embryonic and 9 postnatal motoneurons. Similar size glycinergic and GABAergic unitary currents were recorded at both ages. * Significantly different than at E17-18, $P<0.05$. $\dagger$ Significantly different than GlyR-mediated mIPSCs at the same age, $P<0.05$. $\ddagger$ Error derived from sampled mIPSCs. 
A strychnine
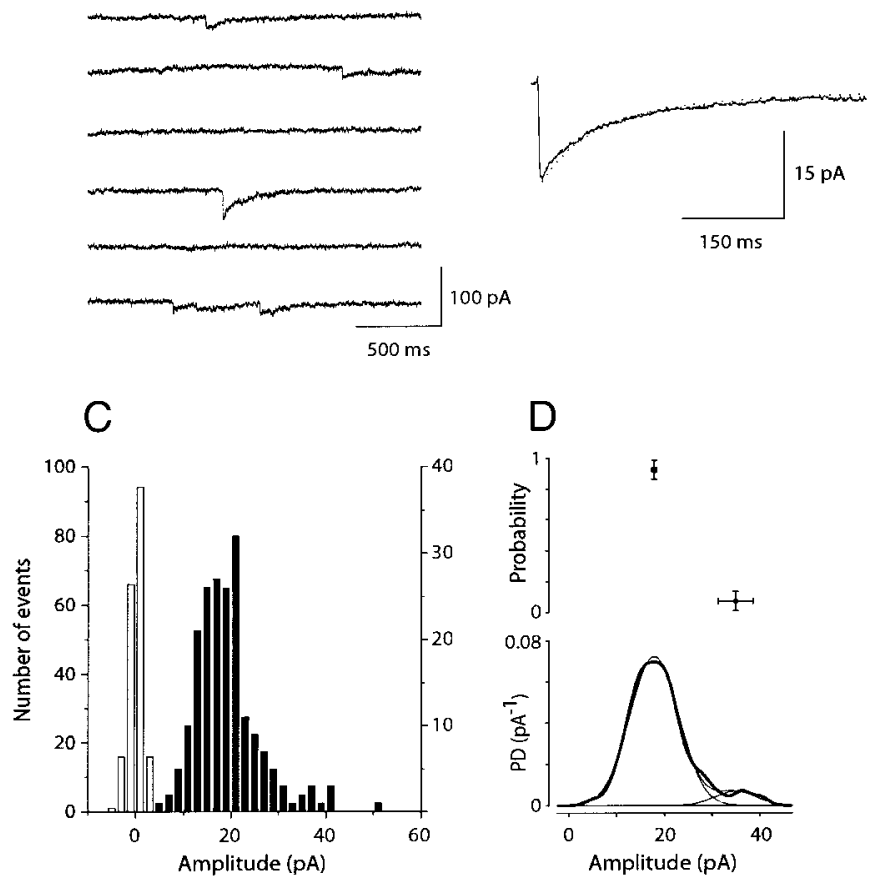

B

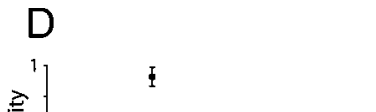

FIG. 6. Properties of $\mathrm{GABA}_{\mathrm{A}} \mathrm{R}$-mediated mIPSCs recorded in a $P 1$ motoneuron. In the presence of strychnine, mIPSC frequency was $0.3 \mathrm{~Hz}(A)$. Rise time of the averaged mIPSC ( $n=197$ events) was $3.0 \mathrm{~ms}$, and decay $\tau 1$ and $\tau 2$ were 70.5 and $353.5 \mathrm{~ms}$, respectively $(B)$. Amplitude histograms of mIPSCs and noise fluctuations are shown in $C$. PD as a function of mIPSC amplitude, generated from a sample size of 195 observations and based on a noise standard deviation of $1.6 \mathrm{pA}(D)$. mIPSC amplitudes larger than $40 \mathrm{pA}$ were removed to minimize the bias of the estimates. Two discrete components were identified at $17.9 \pm 0.6$ and $34.8 \pm 3.6 \mathrm{pA}(D$, bottom). The associated standard deviations were $5.1 \pm 0.4$ and $4.3 \pm 1.5 \mathrm{pA}$, respectively. The component probabilities were $0.93 \pm 0.06$ and $0.07 \pm 0.06$ ( $D$, top $)$.

$\mathrm{pA}(n=5)$ at $E 17-18$, similar to the $22.7 \pm 2.5 \mathrm{pA}(n=9)$ recorded after birth (Table 2). PDF analyses showed that in $80 \%$ of E17-18 motoneurons $(n=4 / 5)$, mIPSC amplitude fluctuations were best fitted by a unimodal skewed distribution (Fig. 5D), and in only one motoneuron the PDF was best described by a two-component Gaussian mixture. Unimodal skewed distributions might be the result of large quantal variability (intrasite and/or intersite variability) and/or "smeared" peaks due to small signal-to-noise ratio caused by either a large recording noise or a small quantal size. However, it is unlikely that the skewed distribution resulted from a small signal-to- noise ratio, because similar averaged currents were recorded in embryonic and postnatal motoneurons, but in most postnatal neurons, mIPSC amplitudes were best described by multicomponent Gaussian curves rather than skewed distribution (Fig. $6 D$ and Table 2).

A significant change in mIPSC amplitude fluctuations was evident after birth, when amplitude distributions in 78\% ( $n=$ 7/9) of motoneurons were best fitted with a Gaussian mixture consisting of two to three discrete components. The size of the first component was $17.9 \pm 2.9 \mathrm{pA}(n=7)$, not significantly smaller than the first component of glycinergic currents.

The decay time of $\mathrm{GABA}_{\mathrm{A}} \mathrm{R}$-mediated mIPSCs significantly decreased postnatally, as evident by faster decay $\tau \mathrm{s} . \tau 1$ changed from $90.1 \pm 12.4 \mathrm{~ms}(n=7)$ at $E 17-18$ to $60.8 \pm 5.9$ $\mathrm{ms}(n=11)$ at $P 1-3$, and $\tau 2$ decreased from $437.1 \pm 68.3 \mathrm{~ms}$ to $303.8 \pm 29.7 \mathrm{~ms}$ during the same period (Table 2). Similar to GlyR-mediated mIPSCs, $\tau 1$ contributed $66 \%$ to the peak amplitude, and amplitude-weighted averaged decay $\tau \mathrm{s}$ were $220.1 \pm 31.8(n=7)$ and $143.4 \pm 13.5 \mathrm{~ms}(n=11)$ in embryonic and postnatal motoneurons, respectively.

The average decay $\tau \mathrm{S}$ of $\mathrm{GABA}_{\mathrm{A}} \mathrm{R}$-mediated mIPSCs were four- to sevenfold slower than those of GlyR-mediated mIPSCs. This was partly due to the effect of flunitrazepam (Flu, 2 $\mu \mathrm{M}$ ), which selectively prolongs the duration of GABAergic but not glycinergic synaptic currents (Nusser et al. 1997). However, even in the absence of Flu, the decay $\tau \mathrm{s}$ of GABAergic mIPSCs were two- to fourfold slower than those of glycinergic currents (not shown).

\section{Properties of mixed GlyR-and GABA $A_{A}$-mediated mIPSCs}

At the beginning of each experiment, before GlyR- or $\mathrm{GABA}_{\mathrm{A}} \mathrm{R}$-mediated mIPSCs were blocked, three types of mIPSCs were apparent: fast-decaying glycinergic mIPSCs, slowdecaying GABAergic mIPSCs and dual-component, mixed fast- and slow-decaying currents (Fig. 7). These dual-component mIPSCs were not observed in the presence of either bicuculline or strychnine, suggesting that they were generated by simultaneous activation of colocalized glycine and $\mathrm{GABA}_{\mathrm{A}}$ receptors.

To determine the contribution of pure glycinergic and GABAergic synaptic sites and mixed glycine-GABA sites to spontaneous inhibitory transmission, the three mIPSC subpopulations were kinetically isolated based on their decay $\tau \mathrm{s}$. In each motoneuron, the averaged traces of pharmacologically isolated glycinergic and GABAergic mIPSCs were used as control

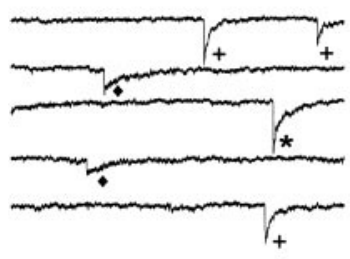

bicuculline

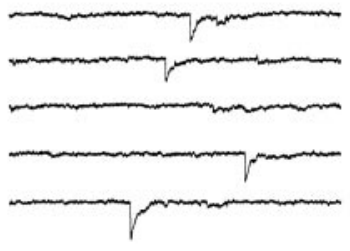

strychnine

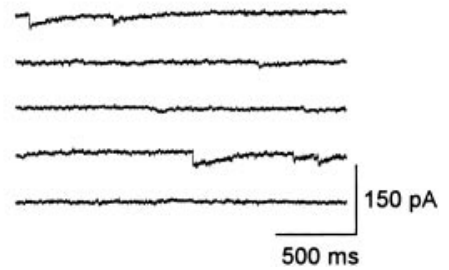

FIG. 7. Three types of mIPSCs recorded in a $P 1$ motoneuron. Left: mIPSCs recorded at a HP of $-60 \mathrm{mV}$ in the absence of strychnine and bicuculline (control). Three subpopulations of mIPSCs were apparent: fast-decaying mIPSCs $(+)$, slow-decaying mIPSCs $(\bullet)$ and dual-component, fast- and slow-decaying mIPSCs $(*)$. Middle: bicuculline-resistant, fast-decaying glycinergic mIPSCs. Right: strychnine-resistant, slow-decaying GABAergic mIPSCs. Bicuculline $(5 \mu \mathrm{M})$ was removed from the extracellular solution, and the slice was perfused for $30 \mathrm{~min}$ before strychnine application. Recordings were performed 14 min after strychnine $(0.5 \mu \mathrm{M})$ was added to the extracellular solution. 
Pharmacologically isolated mIPSCs

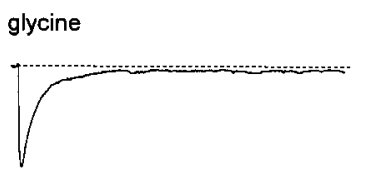

GABA

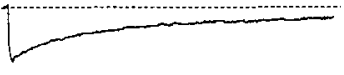

Kinetically isolated mIPSCs

glycine

GABA
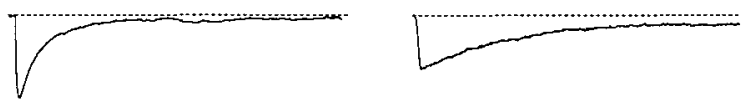

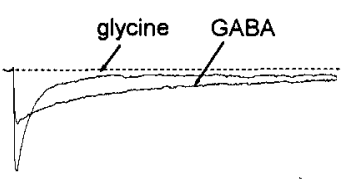

glycine-GABA

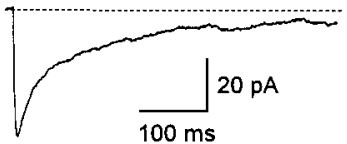

FIG. 8. Similar properties characterized the averaged pharmacologically and kinetically isolated mIPSCs in a $P 2$ motoneuron. GlyR- and GABA $\mathrm{A}_{\mathrm{A}}$ mediated mIPSCs were pharmacologically isolated in the presence of bicuculline and strychnine, respectively. Averaged GlyR-mediated mIPSC ( $n=$ 502 events) and $\mathrm{GABA}_{\mathrm{A}} \mathrm{R}$-mediated mIPSC $(n=$ 189) were superimposed to show that the decay time of $\mathrm{GABA}_{\mathrm{A}} \mathrm{R}$-mediated mIPSCs was significantly slower than that of GlyR-mediated mIPSCs. Pharmacologically isolated mIPSCs were used as templates to distinguish between glycinergic and GABAergic mIPSCs based on their kinetic properties. The averaged mixed glycine-GABA mIPSC had a dual-component decay time that resembled the fast- and slow-decaying phases of the superimposed GlyR- and GABA ${ }_{\mathrm{A}}$ R-mediated mIPSCs. templates to distinguish between the three types of mIPSCs (Fig. 8). Individual mIPSCs were classified as pure glycinergic or GABAergic if their decay $\tau 1$ and $\tau 2$ were within $\pm 1 \mathrm{SD}$ of the averaged decay $\tau \mathrm{s}$ of GlyR- and $\mathrm{GABA}_{\mathrm{A}} \mathrm{R}$-mediated mIPSCs. Two criteria were required to distinguish the dual-component, fast-slow-decaying mIPSCs from the pure mIPSCs: 1) decay $\tau 1$ was more than \pm 1 SD faster than $\tau 1$ of $\mathrm{GABA}_{\mathrm{A}} \mathrm{R}$ mediated mIPSC, and 2) decay $\tau 2$ was at \pm 1 SD of the average decay $\tau 2$ of GABA $_{A}$ R-mediated mIPSCs. It is conceivable that the fraction of dual-component mIPSCs in the total mIPSC population was slightly underestimated, because in $<10 \%$ of mIPSCs with obvious fast-slow-decaying components, the decay could not be fitted well with two exponentials. Those mIPSCs were not included in the analysis. An example of the three mIPSC subpopulations isolated based on their kinetic properties is shown in Fig. 8.

Figure 9 shows an example of averaged dual-component glycine-GABA-mediated mIPSC in a $P 2$ motoneuron. The finding that the monotonic rise time of dual-component mIPSCs was similar to that of GlyR- and GABA ${ }_{A}$ R-mediated mIPSCs (Tables 2 and 3 ) supported the assumption that those mIPSCs were produced by simultaneous activation of glycine

A

B

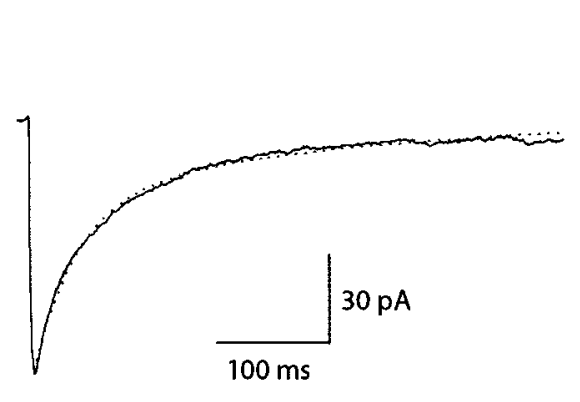

and GABA receptors. In both embryonic and postnatal motoneurons, decay times of the dual-component mIPSCs were slower than the decay times of glycinergic mIPSCs but faster than those of GABAergic mIPSCs. Mean decay $\tau 1$ was similar to the decay $\tau 1$ averaged between GlyR- and $\mathrm{GABA}_{\mathrm{A}} \mathrm{R}$-mediated mIPSCs (Table 3 ), and decay $\tau 2$ was within \pm 1 SD of $\tau 2$ of $\mathrm{GABA}_{\mathrm{A}} \mathrm{R}$-mediated mIPSCs. Similar to the developmental decrease of the decay time of GABA $\mathrm{R}$-mediated mIPSCs, the decay time of dual-component mIPSCs was faster after birth.

The frequency of dual-component mIPSCs increased threeto fourfold after birth, changing from $0.06 \pm 0.02 \mathrm{~Hz}$ at E17-18 to $0.21 \pm 0.03 \mathrm{~Hz}$ at $P 1-3$ (Table 3 ). The mean amplitude of the mixed mIPSCs was larger than the mean amplitudes of either pure GlyR- or pure $\mathrm{GABA}_{\mathrm{A}} \mathrm{R}$-mediated mIPSCs. For example, at $P 1-3$ the mean amplitude of pure GlyR- and $\mathrm{GABA}_{\mathrm{A}} \mathrm{R}$-mediated mIPSCs were $42.4 \pm 8.8$ and $22.7 \pm 2.5 \mathrm{pA}$ (Table 2 ), and the mean amplitude of dualcomponent mIPSCs was $68.3 \pm 4.7$ pA (Table 3), approximately an arithmetic sum of the mIPSCs generated by glycine and GABA receptors. The mean amplitude of the currents produced at mixed glycine-GABA synaptic sites did not significantly change after birth. In the example shown in Fig. 9,

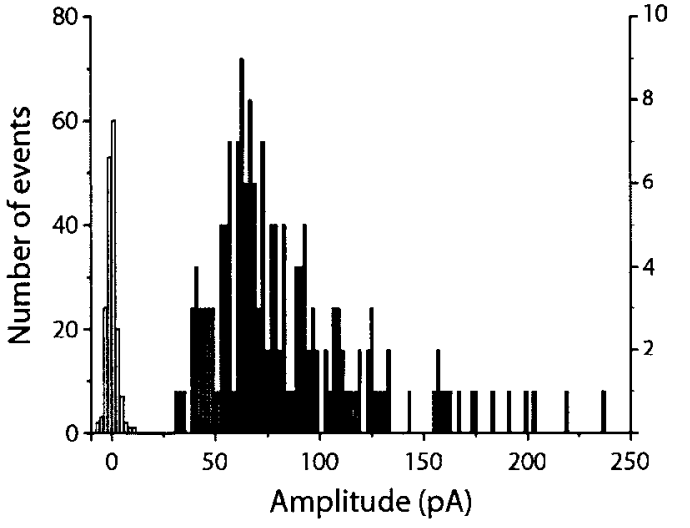

C

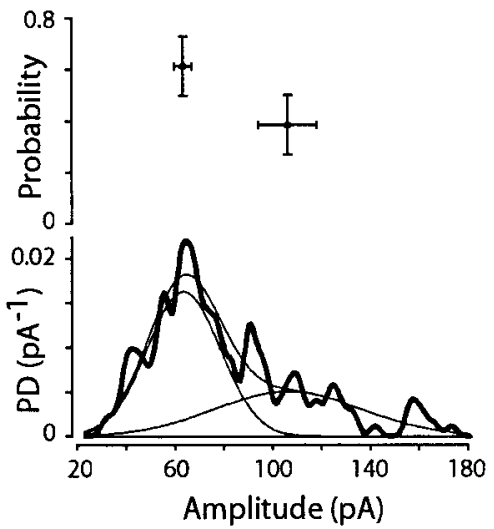

FIG. 9. Averaged dual-component glycine-GABA-mediated mIPSC recorded in a $P 2$ motoneuron. The averaged mIPSC $(n=$ 173) had a rise time of $3.0 \mathrm{~ms}$, and decay $\tau 1$ and $\tau 2$ were 38.1 and $269.9 \mathrm{~ms}$, respectively $(A)$. Amplitude histograms of mIPSCs and noise fluctuations are shown in $B$. PD as a function of mIPSC amplitude was generated from a sample size of 165 observations and based on a noise standard deviation of $2.1 \mathrm{pA}(C)$. To minimize the bias of the estimates, the analysis did not include mIPSCs with amplitudes larger than $180 \mathrm{pA}$. Two distinct components were identified at $63.6 \pm 3.6$ and $106.4 \pm 12.0 \mathrm{pA}(C$, bottom $)$. The associated standard deviations were $15.1 \pm 2.3$ and $30.5 \pm 4.5 \mathrm{pA}$, respectively. The component probabilities were $0.61 \pm 0.12$ and $0.39 \pm 0.12(C$, top $)$. 
TABLE 3. Properties of mixed glycine-GABA-mediated mIPSCs in embryonic and postnatal motoneurons

\begin{tabular}{lrccccc}
\hline \hline & $n$ & Frequency, Hz & Mean Amplitude, pA & Rise Time, ms & Decay $\tau 1$, ms & Decay $\tau 2$, ms \\
\hline E17-18 & 7 & $0.06 \pm 0.02$ & $56.8 \pm 9.7$ & $2.3 \pm 0.4$ & $57.8 \pm 4.3$ & $395.7 \pm 76.4$ \\
$P 1-3$ & 11 & $0.21 \pm 0.03^{*}$ & $68.3 \pm 4.7$ & $2.3 \pm 0.3$ & $33.2 \pm 3.3^{*}$ & $245.1 \pm 27.3^{*}$ \\
\hline
\end{tabular}

Values are means $\pm \mathrm{SE} ; n$ is number of motoneurons. The frequency of dual-component mIPSCs increased 3- to 4-fold, and their duration was significantly shorter after birth. * Significantly different than at $E 17-18, P<0.05$.

the probability density as a function of mIPSC amplitude was best fitted by a Gaussian mixture with two components at $63.6 \pm 3.6$ and $106.4 \pm 12.0 \mathrm{pA}$, respectively.

The percentage of each mIPSC subpopulation was determined in individual motoneurons using the kinetic analysis described above. This analysis was preferred over the analysis based on the frequency of pharmacologically isolated mIPSCs, because the kinetic characterization of each MIPSC was carried out for the total population of mIPSCs. Our findings showed that the contribution of pure glycinergic and GABAergic synaptic sites to spontaneous transmission changed between E17-18 and P1-3. GABA $\mathrm{A}$-mediated mIPSCs accounted for $51.4 \pm 2.6 \%$ of the mIPSCs at E17-18, while GlyR-mediated mIPSCs and the dual-component, mixed mIPSCs constituted $23.8 \pm 3.3 \%$ and $24.8 \pm 4.4 \%$ of the total mIPSC population, respectively (Fig. 10). The contribution of glycinergic and GABAergic currents to inhibitory synaptic transmission was reversed after birth when $62.0 \pm 5.4 \%(n=11)$ of the mIPSCs were mediated via glycine receptors and only $17.0 \pm 3.8 \%$ by $\mathrm{GABA}_{\mathrm{A}}$ receptors. The contribution of mixed glycine-GABA synaptic sites to mIPSC generation was $21.0 \pm 2.7 \%$ after birth, similar to their contribution to mIPSC population in embryonic motoneurons.

\section{I S C U S S I O N}

In this study we examined the properties of GlyR- and $\mathrm{GABA}_{\mathrm{A}} \mathrm{R}$-mediated mIPSCs at early stages of neural network formation in the rat spinal cord and determined the relative contribution of the glycinergic and GABAergic systems to spontaneous inhibitory synaptic transmission. Our findings demonstrated that GABAergic synaptic inputs dominated high- $\mathrm{K}^{+}$-induced spontaneous transmission in spinal motoneurons of rat embryos, giving rise to primarily long-duration mIPSCs. Short-duration glycinergic mIPSCs were predominant after birth, indicating a developmental switch from GABAergic to glycinergic synaptic inputs during the period of extensive synaptogenesis. Our study also showed that from early stages of spinal network formation, a small fraction of mIPSCs was generated by the coactivation of glycine and $\mathrm{GABA}_{\mathrm{A}}$ receptors at mixed synaptic sites.

\section{Developmental changes in the properties of pure glycinergic and GABAergic mIPSCs}

The most striking developmental change in the composition of mIPSC population was the eightfold postnatal increase inthe ratio of the frequency of glycine-to-GABA-mediated mIPSCs.
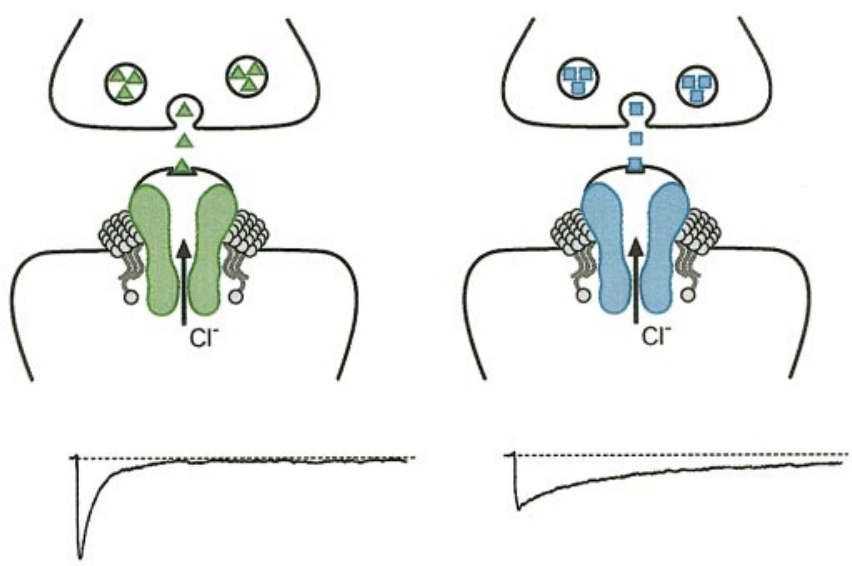

\section{GlyR-mediated mIPSC GABA $_{A}$ R-mediated mIPSC GlyR-GABA $A$ R-mediated mIPSC}

$\begin{array}{cccc}\text { E17-18 } & 24 \pm 3 \% & 51 \pm 3 \% & 25 \pm 4 \% \\ \text { P1-3 } & 62 \pm 5 \% & 17 \pm 4 \% & 21 \pm 3 \%\end{array}$

FIG. 10. Developmental switch from predominantly GABAergic synaptic sites at E17-18 to glycinergic sites at P1-3. Pure $\mathrm{GABA}_{\mathrm{A}} \mathrm{R}$-mediated mIPSCs constituted $51.4 \pm 2.6 \%$ of mIPSC population at E17-18, while the contributions of pure GlyRmediated mIPSCs and mixed GlyR-GABA ${ }_{\mathrm{A}} \mathrm{R}$-mediated mIPSCs were $23.8 \pm 3.3 \%$ and $24.8 \pm 4.4 \%$, respectively. The contribution of GlyR-mediated mIPSCS to the total population increased to $62.0 \pm 5.4 \%$ at $P 1-3$, while $\mathrm{GABA}_{\mathrm{A}} \mathrm{R}$-mediated mIPSCs and the mixed GlyR-GABA ${ }_{A} \mathrm{R}$-mediated mIPSCs constituted only $17.0 \pm 3.8 \%$ and $21.0 \pm 2.7 \%$, respectively. 
Two mechanisms might explain the postnatal increase in thefrequency of GlyR-mediated mIPSCs: the establishment of new functional glycinergic synaptic sites and/or an increase in the probability of glycine release. It is unlikely that the increase in glycinergic synaptic sites in the developing spinal cord was associated with a reduction in the number of GABAergic active sites, because the frequency of $\mathrm{GABA}_{\mathrm{A}} \mathrm{R}$-mediated currents remained unchanged during the period studied. A transition from GABAergic to glycinergic synaptic transmission that is correlated with a decrease in the number of GABAergic synaptic sites has been demonstrated in the gerbil lateral superior olive during the first two postnatal weeks (Kotak et al. 1998).

An increased probability of glycine release might be attributed to developmental changes in structural factors such as increased $\mathrm{Ca}^{2+}$ channel density or an increase in the number of available glycine-containing vesicles. Although we cannot rule it out, it is unlikely that high extracellular $\mathrm{K}^{+}$differentially affected glycine but not GABA release in an age-dependent manner, triggering higher frequency of GlyR-mediated mIPSCs in postnatal but not in embryonic motoneurons. If the increased frequency primarily resulted from an increased probability of transmitter release, the shapes of the mIPSC PDFs were expected to be more symmetrical than in embryonic motoneurons. In contrast, our data demonstrated slightly longer tails of the PDFs that were fitted with additional Gaussian components. A small increase in probability of multi-vesicular release might explain the additional Gaussian components that were apparent after birth.

This study demonstrated that the mean amplitude of glycinergic mIPSCs increased twofold after birth, while there was no significant change in the amplitude of pure GABAergic and mixed glycine-GABA currents. The postnatal increase in the amplitude of GlyR-mediated mIPSCs is correlated with an eightfold postnatal increase in glycine current density produced by pressure ejection of glycine onto motoneuron somata (Gao and Ziskind-Conhaim 1995). Similar to our findings, that study also showed that there was no change in GABA-activated currents. The increased glycine current density might be indicative of the formation of new glycinergic synaptic sites, which provides additional support for the observed increase in the frequency of GlyR-mediated mIPSCs.

Our findings showed that the first component in the amplitude distributions of neither GlyR- nor $\mathrm{GABA}_{\mathrm{A}} \mathrm{R}$-mediated mIPSCs changed after birth. If the first component reflected the size of the unitary current, the finding suggested that there was no change in the quantal size during the period studied. The size of the first component within the mixture might have been biased by the way the detection threshold was set to recover the mIPSCs. The extent of the bias was most likely small as the first component had a significantly larger standard deviation than the recording noise. Whereas, if the density had been affected by truncation due to the detection threshold, the first component would have had a standard deviation of roughly the size of the recording noise. The size of unitary currents measured in our study corresponded well with the quantal size of $\mathrm{GABA}_{\mathrm{A}} \mathrm{R}$-mediated synaptic currents recorded in neurons in hippocampal slices, which varied between 7 and $20 \mathrm{pA}$ at a holding potential of $-50 \mathrm{mV}$ (Edwards et al. 1990). Smaller GABAergic unitary currents of $6-8 \mathrm{pA}$ were estimated from the mean separation of equally distanced Gaussian peaks in neocortical pyramidal cells (Ling and Benardo 1999).
Based on the quantal theory of transmitter release, the amplitude of miniature currents is determined by several factors including the size of the vesicular content, the concentration and time course of neurotransmitter in the synaptic cleft, the number of available postsynaptic receptors, and the distance of the synapses from the recording site (reviewed by Walmsley et al. 1998). It is generally assumed that if vesicular content is sufficient to saturate the postsynaptic receptors, an increase in the magnitude of the unitary current would reflect either an increase in the number of available postsynaptic receptors or a larger channel conductance. For example, it has been shown that the size of glycinergic receptor clusters is a fundamental factor that determines mIPSC amplitude in spinal cord interneurons (Oleskevich et al. 1999). Similarly, the quantal amplitude of GABAergic mIPSCs in cerebellar stellate cells is determined primarily by the number of postsynaptic $\mathrm{GABA}_{\mathrm{A}}$ receptors (Nusser et al. 1997).

Our findings that the size of glycinergic and GABAergic unitary current did not change postnatally might imply that the developmental increase in GlyR-mediated mIPSC amplitudes resulted, at least in part, from increased multiquantal release and not from increased density of glycinergic receptors at synaptic sites. The observations that, in most motoneurons, the multiple components in Gaussian curves were spaced equidistantly support the concept that mIPSC amplitudes varied quantally. However, it should be noted that for simplicity, we chose to fit Gaussians with variable means and standard deviations. We cannot exclude the possibility that the modes resulted from another process that may have been skewed.

The kinetic properties of GlyR- and $\mathrm{GABA}_{\mathrm{A}} \mathrm{R}$-mediated mIPSCs recorded in P1-3 motoneurons were similar to those reported in brain stem motoneurons of $P 1-5$ rats (O'Brien and Berger 1999). In both groups of motoneurons, the rise time of glycinergic and GABAergic mIPSCs was about $2 \mathrm{~ms}$, and the decay $\tau 1$ of GlyR-mediated mIPSCs was shorter than $15 \mathrm{~ms}$, while the decay $\tau 1$ of $\mathrm{GABA}_{\mathrm{A}} \mathrm{R}$-mediated mIPSCs was shorter or equal to $60 \mathrm{~ms}$. Comparison of our data with findings from spinal motoneurons of $P 5-10$ rats (Jonas et al. 1998) indicated that amplitude-weighted mean decay $\tau \mathrm{S}$ of $\mathrm{GABA}_{\mathrm{A}} \mathrm{R}$-mediated mIPSCs were similar at both ages. However, the mean decay $\tau$ of GlyR-mediated mIPSCs recorded in our study was $33 \mathrm{~ms}$, significantly slower than the $15 \mathrm{~ms}$ reported in the older motoneurons. It is possible that the difference was age related. A developmental decrease in the mean decay $\tau \mathrm{s}$ of glycinemediated evoked IPSCs has been reported in spinal sensory neurons, changing from $27 \mathrm{~ms}$ at $E 20$ to $17.8,12.0$, and $5.9 \mathrm{~ms}$ at P4, P8, and P16, respectively (Takahashi et al. 1992). That study demonstrated that the shorter decay times are correlated with a switch in glycine receptor subunits from the embryonic $\alpha 2$ to the adult $\alpha 1$ subunit.

Our finding that the decay time constants of $\mathrm{GABA}_{\mathrm{A}} \mathrm{R}$ mediated mIPSCs decreased after birth confirmed previous reports showing similar changes in the decay kinetics of GABAergic postsynaptic currents at different stages of cortical and hippocampal neurons (Dunning et al. 1999; Taketo and Yoshioka 2000). Those studies attributed the shorter decay times to changes in $\alpha$-subunit composition of $\mathrm{GABA}_{\mathrm{A}}$ receptors. 
Contribution of mixed glycine-GABA synaptic sites to synaptic inhibition

Our findings suggested that a fraction of mIPSCs with fast monotonic rise time and fast- and slow-decaying components were generated by the co-release of glycine and GABA from the same synaptic vesicles and the activation of co-localized glycine and $\mathrm{GABA}_{\mathrm{A}}$ receptors at postsynaptic sites. Similar findings have been reported in spinal and hypoglossal motoneurons (Jonas et al. 1998; O'Brien and Berger 1999). Immunohistochemical studies have documented that glycine and GABA are coexpressed in nerve terminals in the adult rat spinal cord (Örnung et al. 1994; Somogyi and Llewellyn-Smith 2000; Todd and Sullivan 1990), and glycine and GABA receptors are co-localized at postsynaptic sites (Bohlhalter et al. 1994; Todd et al. 1996). Based on those findings it has been hypothesized that the inhibitory amino acids might act synergistically on target neurons, but the relevance of such specific structural organization to the integration of inhibitory synaptic inputs has only recently been studied. The mIPSCs generated by simultaneous activation of both GlyR- and GABA ${ }_{A}$ R-mediated $\mathrm{Cl}^{-}$-dependent channels had an average amplitude that was approximately the arithmetic sum of glycinergic and GABAergic unitary currents. The ability to modulate the amplitude and time course of postsynaptic inhibitory synaptic currents by regulating the amount of glycine and GABA released from the presynaptic interneuron might serve as a finetuning mechanism for synaptic integration and motor coordination. Furthermore, in pure glycinergic synapses the release of glycine is not affected by $\mathrm{GABA}_{\mathrm{B}}$ receptor-mediated presynaptic inhibition, but in the case of mixed synaptic sites, the co-release of glycine and GABA from the same nerve terminal might provide a feedback control of the release of both neurotransmitters.

The contribution of mixed glycine-GABA synaptic sites to the generation of mIPSCs did not significantly change during the 8 -day period, changing from $25 \%$ before birth to $21 \%$ after birth. Higher percentage (44\%) of mixed glycine-GABA synaptic specialization has been reported in motoneurons of $P 5-10$ rats (Jonas et al. 1998), and in adult rats (46\%) (Somogyi and Llewellyn-Smith 2000), indicating that at later ages the mixed glycine-GABA synapses play a more substantial role in mediating inhibitory synaptic transmission than at early stages of neural network formation.

\section{Functional significance of the switch from GABAergic to glycinergic spontaneous transmission}

The developmental transition from GABAergic to glycinergic synaptic transmission might have important functional implication in regulating synaptic integration in the developing spinal cord. The relatively long-duration GABAergic currents might serve as an effective mechanism for controlling the level of neuronal excitation at a period when motoneurons are incapable of firing repetitive action potentials (Gao et al. 1998; Xie and Ziskind-Conhaim 1995). The postnatal predominance of the shorter duration glycinergic currents is correlated with the generation of faster and larger amplitude action potential and the ability of motoneurons to fire repetitive action potentials.

It has been suggested that in addition to its role in mediating synaptic transmission, GABA functions as a regulatory signal during development (Lauder 1993; Spoerri 1988; ZiskindConhaim 1998). The neurotrophic function of GABA might be related to its effect on intracellular $\mathrm{Ca}^{2+}$ concentration (Connor et al. 1987; Lo et al. 1998). Glycine and GABA depolarize spinal neurons during embryonic and postnatal development (Gao and Ziskind-Conhaim 1995; Takahashi 1984; Wang et al. 1994; Wu et al. 1992), resulting in the activation of voltagedependent $\mathrm{Ca}^{2+}$ channels and a transient elevation in intracellular $\mathrm{Ca}^{2+}$ (e.g., Reichling et al. 1994; Ziskind-Conhaim 1998). Although both amino acids are capable of increasing cytoplasmic $\mathrm{Ca}^{2+}$, the long-duration GABAergic currents are probably more effective in triggering $\mathrm{Ca}^{2+}$-dependent cellular mechanisms underlying neural development and synaptogenesis in the spinal cord (Fields and Nelson 1993; Kocsis et al. 1993; Spitzer 1994).

We are grateful to Drs. Steve Redman and Anna Cowan for providing critical comments on the manuscript.

This research was supported by National Institute of Neurological Disorders and Stroke Grant NS-23808 to L. Ziskind-Conhaim.

\section{REFERENCES}

BOHLHALTER S, MOHLER H, AND FritsChy J-M. Inhibitory neurotransmission in rat spinal cord: co-localization of glycine- and $\mathrm{GABA}_{\mathrm{A}}$-receptors at GABAergic synaptic contacts demonstrated by triple immunofluorescence staining. Brain Res 642: 59-69, 1994.

Chaudhry FA, Reimer RJ, Bellocchio EE, Danbolt nC, Osen KK, EdWARDS RH, AND STORM-MATHISEN J. The vesicular GABA transporter, VGAT, localizes to synaptic vesicles in sets of glycinergic as well as GABAergic neurons. J Neurosci 18: 9733-9750, 1998.

CHÉRY N AND KONINCK YD. Junctional versus extrajunctional glycine and $\mathrm{GAGA}_{A}$ receptor-mediated IPSCs in identified lamina I neurons of the adult rat spinal cord. J Neurosci 19: 7342-7355, 1999.

CONNOR JA, TSEng HY, AND Hockberger PE. Depolarization- and transmitter-induced changes in intracellular $\mathrm{Ca}^{2+}$ of rat cerebellar granule cells in explant cultures. J Neurosci 7: 1384-1400, 1987.

CurTis DR, Hosli L, AND Johnston GAR. A pharmacological study of the depression of spinal neurons by glycine and related amino acids. Exp Brain Res 6: 1-18, 1968.

DAVIDOFF RA AND HACKMAN JC. Drugs, chemicals and toxins: their effects on the spinal cord. In: Handbook of the Spinal Cord, edited by Davidoff RA. New York: Dekker, 1983, p. 409-476.

DEL CASTILLO J AND KATZ B. Quantal components of the endplate potentials. J Physiol (Lond) 124: 560-573, 1954.

DunNing DD, Hoover CL, Soltesz I, SMith MA, AND O'Dowd DK. GABA receptor-mediated miniature postsynaptic currents and $\alpha$-subunit expression in developing cortical neurons. J Neurophysiol 82: 3286-3297, 1999.

EDWARDS FA, KonNerTh A, AND SAKMANN B. Quantal analysis of inhibitory synaptic transmission in the dentate gyrus of rat hippocampal slices: a patch-clamp study. J Physiol (Lond) 430: 213-249, 1990.

FIELDS RD AND NELSON PG. Resonant activation of calcium signal transduction in neurons. J Neurobiol 25: 281-293, 1993.

Gao B-X, Cheng G, and Ziskind-Conhaim L. Development of spontaneous synaptic transmission in the rat spinal cord. J Neurophysiol 79: 2277-2287, 1998.

GaO B-X and Ziskind-Conhaim L. Development of glycine- and GABAgated currents in rat spinal motoneurons. J Neurophysiol 74: 113-121, 1995.

GaO B-X And Ziskind-ConHaim L. The roles of glycine and GABA in mediating inhibitory synaptic currents change during development of the rat spinal cord. Soc Neurosci Abstr 25: 1918, 1999.

Gosh A, GinTy DD, BADING H, AND GREenberg ME. Calcium regulation of gene expression in neuronal cells. J Neurobiol 25: 281-293, 1993.

ISAACSON JS AND WALMSLEY B. Counting quanta: direct measurements of transmitter release at a central synapse. Neuron 15: 875-884, 1995.

JonAs P, BISCHOFBerger J, AND SANDKUHLER J. Corelease of two fast neurotransmitters at a central synapse. Science 281: 419-424, 1998.

KOCSIS JD, RAND MN, LANKFORD KL, AND WAXMAN SG. Intracellular calcium mobilization and neurite outgrowth in mammalian neurons. J Neurobiol 25: 252-264, 1993. 
Kotak VC, Korada S, Schwartz IR, and Sanes DH. A developmental shift from GABAergic to glycinergic transmission in the central auditory system. J Neurosci 18: 4646-4655, 1998.

Krnjevic K, Puil E, and Werman R. GABA and glycine action on spinal motoneurons. Can J Physiol Pharmacol 55: 658-669, 1977.

KUdo N AND YAMAdA T. Morphological and physiological studies of development of the monosynaptic reflex pathway in the rat lumbar spinal cord. J Physiol (Lond) 389: 441-459, 1987.

LAUDER JM. Neurotransmitters as growth regulatory signals: role of receptors and second messengers. Trends Neurosci 16: 233-240, 1993.

LING DSF AND BENARDO LS. Restrictions on inhibitory circuits contribute to limited recruitment of fast inhibition in rat neocortical pyramidal cells. J Neurophysiol 82: 1793-1807, 1999.

Lo YJ, RAO SC, AND SANES DH. Modulation of calcium by inhibitory systems in the developing auditory system. Neuroscience 83: 1075-1084, 1998.

MA W, BEHAR T, AND BARKER JL. Transient expression of GABA immunoreactivity in the developing rat spinal cord. J Comp Neurol 325: 271-290, 1992.

MACVICAR BA. Infrared video microscopy to visualize neurons in the in vitro brain slice preparation. J Neurosci Methods 12: 133-139, 1984.

Meier E, Hertz L, And Schousboe A. Neurotransmitters as developmental signals. Neurochem Int 19: 1-15, 1991.

Mellor JR AND RANDALl AD. Frequency-dependent actions of benzodiazepines on $\mathrm{GABA}_{\mathrm{A}}$ receptors in cultured murine cerebellar granule cells. J Physiol (Lond) 503: 353-369, 1997.

Nusser Z, Cull-Candy S, and Farrant M. Differences in synaptic GABA $A_{A}$ receptor number underlie variation in GABA mini amplitude. Neuron 19: 697-709, 1997.

O'BRIEN JA AND BERGER AJ. Cotransmission of GABA and glycine to brain stem motoneurons. J Neurophysiol 82: 1638-1641, 1999.

Oleskevich S, Alvarez FJ, AND Walmsley B. Glycinergic miniature synaptic currents and receptor cluster sizes differ between spinal cord interneurons. J Neurophysiol 82: 312-319, 1999.

Örnung G, Shupliakov O, OtTersen OP, Storm-Mathisen J, ANd Cullheim S. Immunohistochemical evidence for coexistence of glycine and GABA in nerve terminals on cat spinal motoneurons: an ultrastructural study. NeuroReport 5: 889-892, 1994.

REDMAN S. Quantal analysis of synaptic potentials in neurons of the central nervous system. Physiol Rev 70: 165-198, 1990.

Reichling DB, Kyrozis A, Wang J, and MacDermott AB. Mechanisms of GABA and glycine depolarization-induced calcium transients in rat dorsal horn neurons. J Physiol (Lond) 476.3: 411-421, 1994.

SCHNEIDER SP AND FyFFE REW. Involvement of GABA and glycine in recurrent inhibition of spinal motoneurons. J Neurophysiol 68: 397-406, 1992.

Somogyi J AND Llewellyn-Smith IJ. Patterns of colocalization of GABA, glutamate and glycine immunoreactivities in inputs to rat spinal motoneurons. Proc Aust Neuro Soc Abstr 11: 245, 2000.

SPITZER NC. Spontaneous $\mathrm{Ca}^{2+}$ spikes and waves in embryonic neurons: signaling systems for differentiation. Trends Neurosci 17: 115-118, 1994.

SPOERRI PE. Neurotrophic effects of GABA in cultures of embryonic chick brain and retina. Synapse 2: 11-22, 1988.
Stricker C, Daley D, and Redman SJ. Analysis of synaptic transmission: model discrimination and confidence limits. Biophys J 67: 532-547, 1994.

StRicker C AND Redman SJ. Statistical models of synaptic transmission evaluated using the Expectation-Maximization Algorithm. Biophys $J$ 67: 656-670, 1994.

TAKAHASHI T. Inhibitory miniature synaptic potentials in rat motoneurons. Proc R Soc Lond B Biol Sci 221: 103-109, 1984.

Takahashi T, Momiyama A, HiRai K, Hishinuma F, and AKagi H. Functional correlation of fetal and adult forms of glycine receptors with developmental changes in inhibitory synaptic receptor channels. Neuron 9: 1155-1161, 1992.

TAKeto M AND Yoshioka T. Developmental change of $\mathrm{GABA}_{\mathrm{A}}$ receptormediated current in rat hippocampus. Neuroscience 96: 507-514, 2000.

TodD AJ AND SPIKE RC. The localization of classical transmitters and neuropeptides within neurons in laminae I-III of the mammalian spinal dorsal horn. Prog Neurobiol 41: 609-645, 1993.

TODD AJ AND Sullivan AC. Light microscope study of the coexistance of GABA-like and glycine-like immunoreactives in the spinal cord of the rat. J Comp Neurol 296: 496-505, 1990.

Todd AJ, Watt C, Spike RC, and Sieghart W. Colocalization of GABA, glycine, and their receptors at synapses in the rat spinal cord. J Neurosci 16 : 974-982, 1996

Walmsley B, Alvarez FJ, and FyfFe REW. Diversity of structure and function at mammalian central synapses. Trends Neurosci 21: 81-88, 1998.

Walton MK, Schaffner AE, AND BARKER JL. Sodium channels GABA receptors, and glutamate receptors develop sequentially on embryonic rat spinal cord cells. J Neurosci 13: 2068-2084, 1993.

Wang J, Reichling DB, Kyrozis A, and MacDermott AB. Developmental loss of GABA- and glycine-induced depolarization and $\mathrm{Ca}^{2+}$ transients in embryonic rat dorsal horn neurons in culture. Eur J Neurosci 6: 1275-1280, 1994.

WERMAN R, DAVIDOFF RA, AND APRISON MH. Inhibitory action of glycine on spinal neurons in the cat. J Neurophysiol 31: 81-95, 1968.

WU WL, ZISKIND-CONHAIM L, AND SWEET MA. Early development of glycineand GABA-mediated synapses in rat spinal cord. J Neurosci 12: 3935-3945, 1992.

XIE $\mathrm{H}$ and Ziskind-Conhaim L. Blocking $\mathrm{Ca}^{2+}$-dependent synaptic release delays motoneuron differentiation in the rat spinal cord. J Neurosci 15: 5900-5911, 1995.

YoshimuRa M and Nishi S. Primary afferent-evoked glycine- and GABAmediated IPSCs in substantia gelatinosa neurons in the rat spinal cord in vitro. J Physiol (Lond) 482: 29-38, 1995.

Young AB AND MACDONALD RL. Glycine as a spinal cord neurotransmitter. In: Handbook of the Spinal Cord. New York: Dekker, 1983, p. 1-43.

ZISKIND-CONHAIM L. Electrical properties of motoneurons in the spinal cord of rat embryos. Dev Biol 128: 21-29, 1988.

ZISKIND-CONHAIM L. NMDA receptors mediate poly- and monosynaptic potentials in motoneurons of rat embryos. J Neurosci 10: 125-135, 1990.

ZISKIND-Conhaim L. Physiological functions of GABA-induced depolarizations in the developing rat spinal cord. Perspect Dev Neurobiol 5: 279-287, 1998 